\title{
T stage and venous invasion are crucial prognostic factors for long-term survival of patients with remnant gastric cancer: a cohort study
}

\author{
Kentaro Matsuo ${ }^{1}$, Sang-Woong Lee ${ }^{1^{*}} \mathbb{0}$, Ryo Tanaka ${ }^{1}$, Yoshiro Imai ${ }^{1}$, Kotaro Honda ${ }^{1}$, Kohei Taniguchi ${ }^{1,2}$,
} Hideki Tomiyama ${ }^{1}$ and Kazuhisa Uchiyama'

\begin{abstract}
Background: The incidence of remnant gastric cancer (RGC) after distal gastrectomy is $1-5 \%$. However, as the survival rate of patients with gastric cancer improves due to early detection and treatment, more patients may develop RGC. There is no consensus on the surgical and postoperative management of RGC, and the clinicopathological characteristics correlated with the long-term outcomes remain unclear. Therefore, we investigated the clinicopathological factors associated with the long-term outcomes of RGC.

Methods: We included 65 consecutive patients who underwent gastrectomy for RGC from January 2000 to December 2015 at the Osaka Medical and Pharmaceutical University Hospital, Japan. The Kaplan-Meier method was used to create survival curves, and differences in survival were compared between the groups (clinical factors, pathological factors, and surgical factors) using the log-rank test. Multivariate analyses using the Cox proportional hazard model were used to identify factors associated with long-term survival.

Results: No significant differences were noted in the survival rate based on clinical factors (age, body mass index, diabetes mellitus, hypertension, cardiovascular disease, pulmonary complications, liver disease, diet, history of alcohol drinking, and history of smoking) or the type of remnant gastrectomy. Significant differences were noted in the survival rate based on pathological factors and surgical characteristics (intraoperative blood loss, operation time, and the number of positive lymph nodes). Multivariate analysis revealed that the T stage (hazard ratio, 5.593; 95\% confidence interval [CI], 1.183-26.452; $p=0.030$ ) and venous invasion (hazard ratio, 3.351;95\% Cl, 1.030-10.903; $p=0.045$ ) were significant independent risk factors for long-term survival in patients who underwent radical resection for RGC.
\end{abstract}

Conclusions: T stage and venous invasion are important prognostic factors of long-term survival after remnant gastrectomy for RGC and may be keys to managing and identifying therapeutic strategies for improving prognosis in RGC.

Keywords: Remnant gastric cancer, Long-term outcome, Clinicopathological factor, Prognosis

${ }^{*}$ Correspondence: sang-woong.lee@ompu.ac.jp

1 Department of General and Gastroenterological Surgery, Osaka

Medical and Pharmaceutical University, 2-7 Daigaku-machi, Takatsuki, Osaka 569-8686, Japan

Full list of author information is available at the end of the article

\section{Background}

Remnant gastric cancer (RGC) describes all cancers arising from the remnant stomach after partial gastrectomy, regardless of the initial disease or type of gastrectomy [1]. The incidence of RGC after distal gastrectomy has original author(s) and the source, provide a link to the Creative Commons licence, and indicate if changes were made. The images or other third party material in this article are included in the article's Creative Commons licence, unless indicated otherwise in a credit line to the material. If material is not included in the article's Creative Commons licence and your intended use is not permitted by statutory regulation or exceeds the permitted use, you will need to obtain permission directly from the copyright holder. To view a copy of this licence, visit http://creativecommons.org/licenses/by/4.0/. The Creative Commons Public Domain Dedication waiver (http://creativeco mmons.org/publicdomain/zero/1.0/) applies to the data made available in this article, unless otherwise stated in a credit line to the data. 
been reported to be 1-5\% [2-4]. Although the number of patients with RGC who undergo gastrectomy for benign diseases has decreased due to improvements in treatment, more patients with a previous malignant disease are developing RGC because of improved prognosis after gastric cancer [5].

The etiology of RGC is believed to be related to the type of reconstruction. For instance, the anastomotic site of Billroth II reconstruction, which is exposed by bile regurgitation, is a common site of recurrence $[6,7]$. However, non-anastomotic carcinoma occurs more frequently in patients with previous malignancies who have undergone Billroth I reconstruction [8]. Some researchers have reported that the prognosis of advanced RGC is worse than that of primary advanced gastric cancer [9]. However, despite these findings, there has been no consensus on the surgical and postoperative management for RGC, and the clinicopathological characteristics that are correlated with long-term outcomes remain unclear. Data collection on the prognoses of patients with RGC is required to establish an optimal therapeutic strategy for RGC. Herein, we have investigated the clinicopathological factors associated with the long-term outcomes of RGC.

\section{Methods}

\section{Patients}

From January 2000 to December 2015, 65 consecutive patients with RGC underwent gastrectomy at the Osaka Medical College Hospital, Japan. We performed routine workup, including esophagogastroduodenoscopy (EGD) and enhanced computed tomography $(\mathrm{CT})$, for preoperative evaluation. Retrieved specimens were staged using the Japanese Classification of Gastric Carcinoma (15th edition); the depth of tumor invasion was recorded as the pathological $\mathrm{T}$ stage. Tumor morphology was categorized as either superficial (pT1) or advanced (pT2-pT4). Lymph node metastasis was defined using the pathological $\mathrm{N}$ category, and lymphatic invasion and venous invasion were also assessed.

Clinical, surgical, and pathological records of the patients were obtained from our database. Data collection (after receiving written informed consent) and analysis were approved by the Institutional Review Board of the Osaka Medical College (acceptance number: 2020005). Written informed consent was obtained from all participants.

\section{Patient follow-up}

After surgery, blood tests and physical examinations were performed every 3 months, CT was performed every 6 months, and EGD was performed annually. The blood tests also included examination of tumor markers, such as the carcinoembryonic antigen and carbohydrate antigen 19-9. Postoperative adjuvant chemotherapy was not administered to most patients.

The duration of follow-up was 60 months. Thirty-six patients were completely followed up, and 29 were lost to follow-up due to disease-specific death $(n=19)$, death from other causes $(n=3)$, and unknown reasons $(n=7)$.

\section{Statistics}

All statistical analyses were performed using JMP version 15.0 software (SAS Institute Inc., Cary, NC, USA). The Kaplan-Meier method was used to estimate survival curves, and differences in survival were compared using the log-rank test. The cutoff value was set for each factor (age, body mass index [BMI], tumor size, blood loss, operation time, and the number of retrieved lymph nodes and positive lymph nodes) by using a receiver operating characteristic curve analysis.

The multivariate analysis was performed using the Cox proportional hazard models, and $p<0.05$ was considered significant.

\section{Results \\ Patient characteristics}

The clinicopathological and surgical characteristics of the 65 patients are summarized in Tables 1 and 2. The patients comprised 55 men and 10 women. The median age was 71 years (interquartile range, 63.5-76 years). Forty-eight patients (74\%) originally had a malignant disease, and 17 (26\%) had a benign disease. The median interval between original gastrectomy and development of RGC was 10years (interquartile range, 4.25-15years) in patients who originally had a malignant disease, and 30 years (interquartile range, 24.5-42 years) in patients who originally had a benign disease. Total resection of the remnant stomach was performed in 49 patients, while partial resection was performed in 16 patients.

\section{Association of long-term survival with clinical, pathological, and surgical factors}

The overall survival curves based on the clinical characteristics are shown in Fig. 1. There were no significant differences in the survival between patients with values above and below the cut-offs for any of the clinical factors that were examined, including age (older [ $>67$ years] vs. younger $[<67$ years] $)$, BMI, diabetes mellitus, hypertension, cardiovascular disease, pulmonary complications, liver disease, type of original reconstruction, or previous disease history. In addition, overall survival curves based on diet, history of alcohol drinking, and history of smoking are shown in Supplemental Fig. 1.

The overall survival curves based on the pathological characteristics are shown in Fig. 2. There were 
Table 1 Demographic and clinical characteristics of the patients undergoing remnant gastrectomy

\begin{tabular}{ll}
\hline Characteristics & $\begin{array}{l}\text { Patients } \\
(\boldsymbol{n}=65)\end{array}$ \\
\hline Age, years & \\
Median & 71 \\
Interquartile range & $63.5-76$ \\
Sex & \\
Male & $55(84.6 \%)$ \\
Female & $10(15.4 \%)$ \\
ASA & \\
1 & $8(12.3 \%)$ \\
2 & $50(76.9 \%)$ \\
3 & $7(10.8 \%)$ \\
Body mass index, kg/m ${ }^{2}$ & \\
Median & 20.8 \\
Interquartile range & $19.2-23.4$ \\
Previous disease & \\
Benign & 17 \\
Malignant & 48 \\
Previous reconstruction & \\
Billroth I & \\
Billroth II & $23(35.4 \%)$ \\
Others & $20(30.8 \%)$ \\
Years since previous surgery & $22(33.8 \%)$ \\
Median & \\
No. of comorquartile range & 12 \\
0 & $6.5-24.5$ \\
$\geq 3$ & \\
\hline ASA Amies & $37(56.1 \%)$ \\
\hline
\end{tabular}

$A S A$, American Society of Anesthesiologists
Table 2 Demographic, pathological, and surgical characteristics of the patients undergoing remnant gastrectomy

\begin{tabular}{ll}
\hline Characteristic & $\begin{array}{l}\text { Patients } \\
\text { ( } \boldsymbol{n}=65)\end{array}$ \\
\hline Histologic type & \\
Differentiated & $58(89.2 \%)$ \\
Undifferentiated & $7(10.8 \%)$ \\
Pathological T factor & \\
1/2/3/4 & $30 / 7 / 16 / 12$ \\
Pathological N factor & \\
0/1/2/3/X & $43 / 9 / 8 / 1 / 4$ \\
Pathological Stage & \\
I/IIIII/IV & $37 / 10 / 9 / 7$ \\
Type of remnant gastrectomy & \\
Total & $49(73.2 \%)$ \\
Partial & $16(26.8 \%)$ \\
Operation time, min & \\
Median & 320 \\
Interquartile range & $260-372.5$ \\
Blood loss, mL & \\
Median & 310 \\
Interquartile range & $209-515$ \\
Number of retrieved lymph nodes & \\
Median & \\
Interquartile range & 12 \\
Number of positive lymph nodes & 61 (9.1\%) \\
Median & \\
Interquartile range & \\
0 & \\
1-3 & \\
4-20 & $0-19$ \\
X & 43 \\
Adjuvant therapy & \\
Yes & \\
No & \\
\hline & \\
\hline
\end{tabular}

significant differences in the survival rate between patients with values above and below the cut-offs for all pathological factors examined.

The overall survival curves based on each pT stage are shown in Supplemental Fig. 2. There were significant differences in the survival between patients with tumors of different pathological T stages (pT1 and pT2, pT1 and pT3, and pT1 and pT4).

The overall survival curves based on the surgical characteristics are shown in Fig. 3. There were significant differences in the survival rate between patients with values above and below the cut-offs for intraoperative blood loss, operation time, and the number of positive lymph nodes. However, no significant differences in the survival rate were noted between patients who underwent different remnant gastrectomy procedures or between those with values above and below the cutoff for the number of retrieved lymph nodes.

\section{Multivariate analysis of prognostic factors}

Multivariate analysis revealed that the $\mathrm{T}$ stage (hazard ratio, 5.593; 95\% confidence interval $[\mathrm{CI}], 1.183-26.452$; $p=0.030$ ) and venous invasion (hazard ratio, 3.351; 95\% CI, $1.030-10.903 ; p=0.045)$ were significant independent risk factors for the long-term survival of patients who underwent radical resection for RGC (Table 3). 


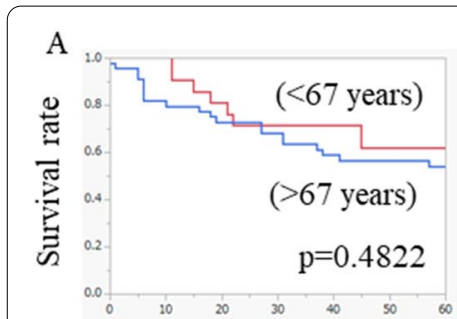

Survival time (months)

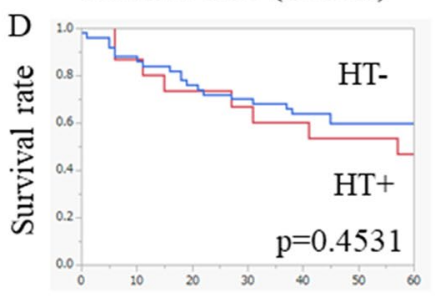

Survival time (months)

G

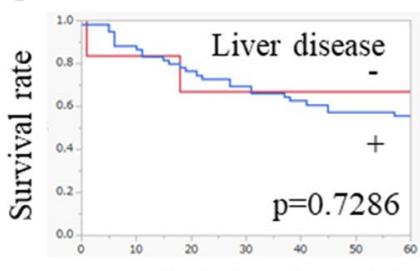

Survival time (months)
B

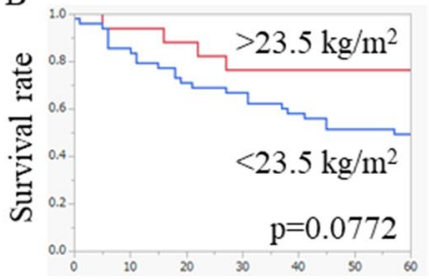

Survival time (months)

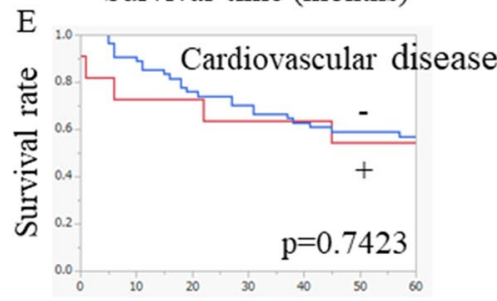

Survival time (months)

$\mathrm{H}$

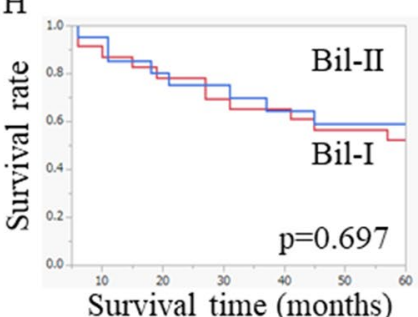

C

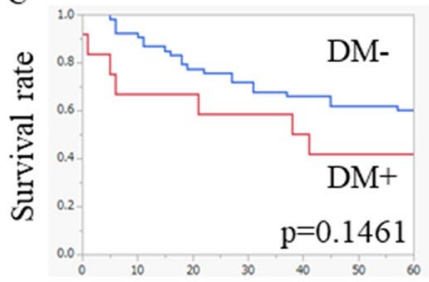

Survival time (months)
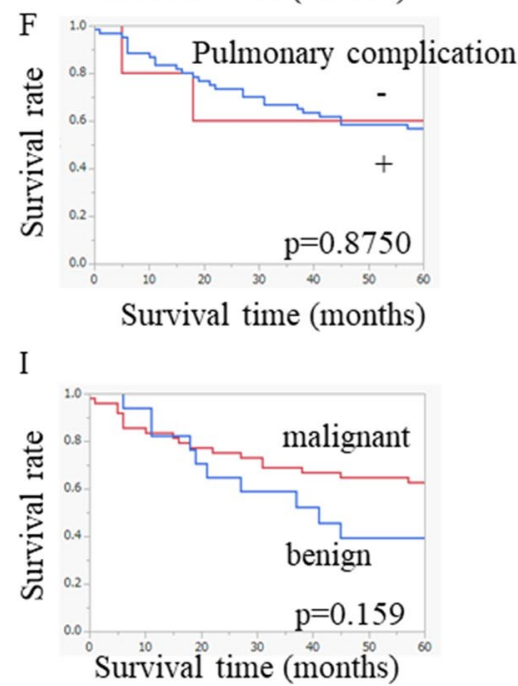

Fig. 1 Long-term survival outcomes based on clinical factors: A age, B body mass index, C diabetes mellitus (DM), D hypertension (HT), E cardiovascular disease, $\mathbf{F}$ pulmonary complications, $\mathbf{G}$ liver disease, $\mathbf{H}$ type of reconstruction, and $\mathbf{I}$ previous disease

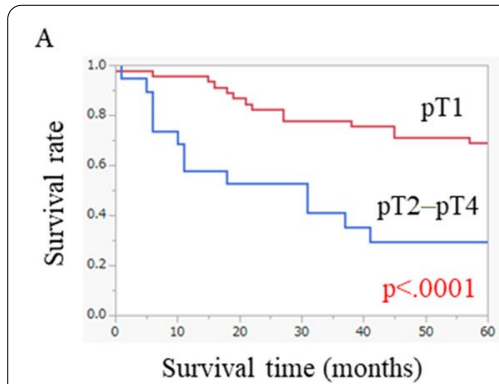

D

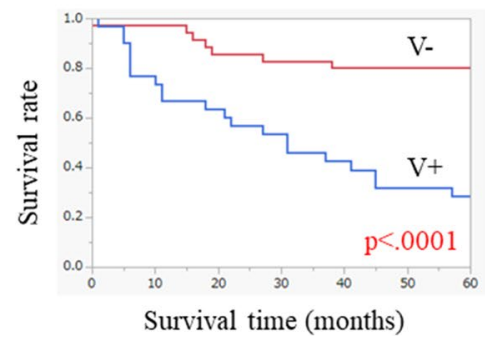

B

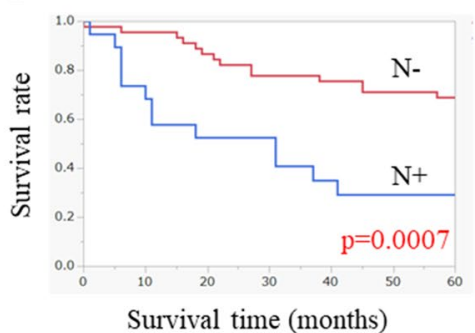

E

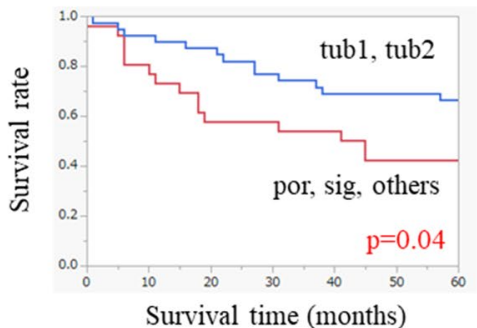

C

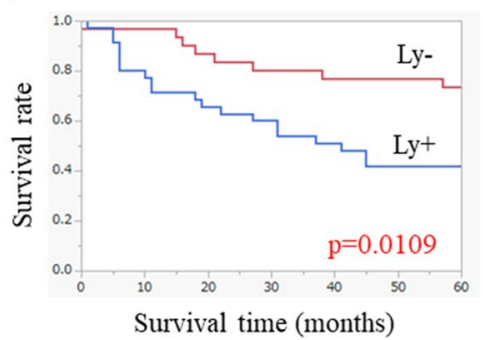

F

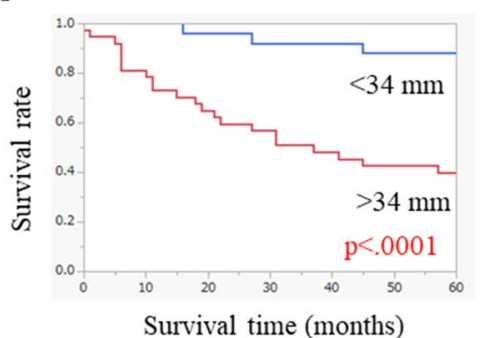

Fig. 2 Long-term survival outcomes based on pathological factors: A pathological T stage, B lymph node metastasis, C lymphatic invasion, D venous invasion, $\mathbf{E}$ histological type, and $\mathbf{F}$ tumor size 

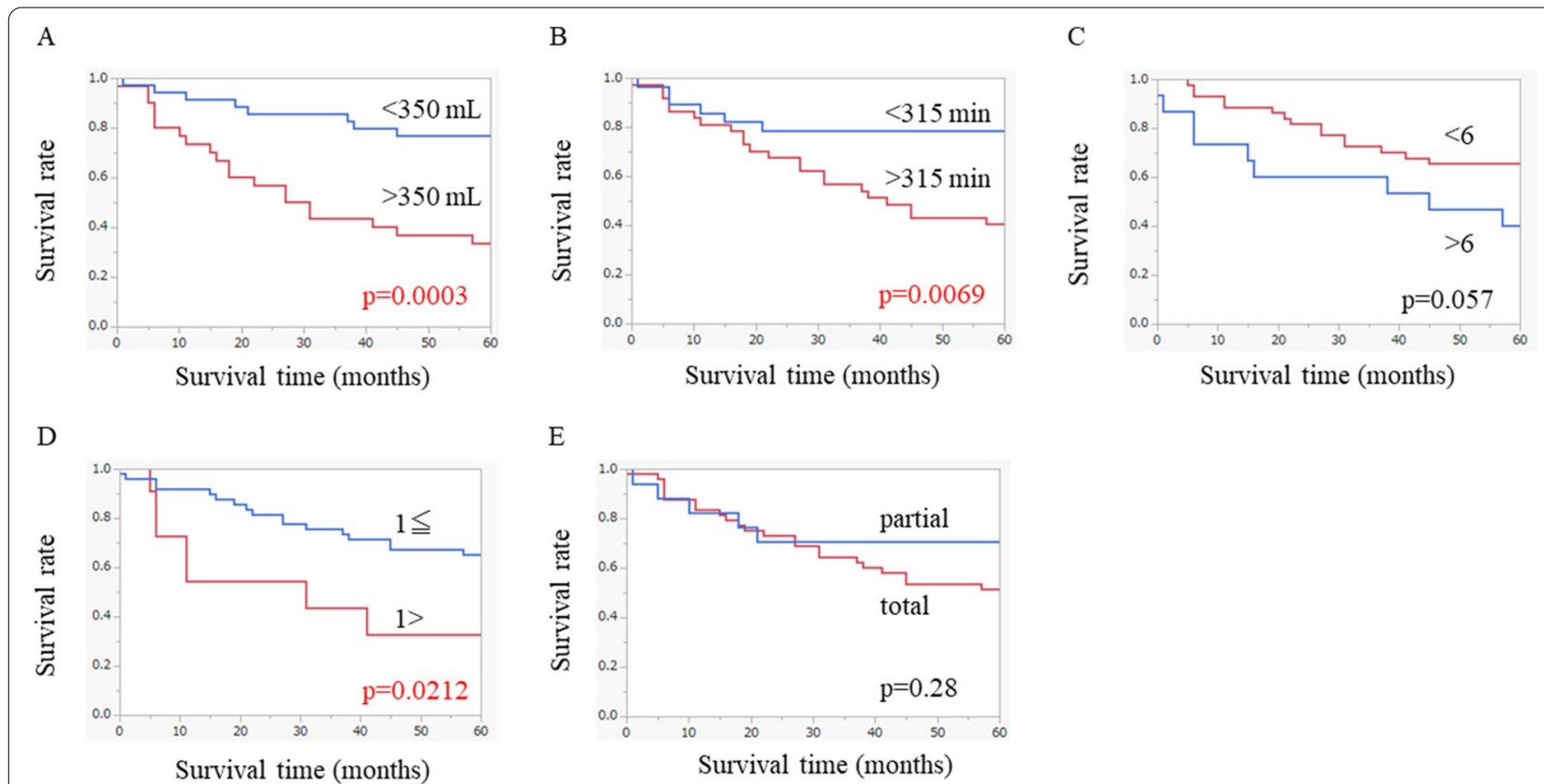

Fig. 3 Long-term survival outcomes based on surgical factors: A intraoperative blood loss, B operation time, C number of retrieved lymph nodes, D number of positive lymph nodes, and $\mathbf{E}$ type of remnant gastrectomy

Table 3 Multivariate analysis of prognostic factors using the Cox proportional hazard model

\begin{tabular}{|c|c|c|c|c|}
\hline Prognostic factors & HR & $\begin{array}{l}95 \% \mathrm{Cl} \\
\text { Lower limit }\end{array}$ & $\begin{array}{l}95 \% \mathrm{Cl} \\
\text { Upper limit }\end{array}$ & $P$ \\
\hline $\begin{array}{l}\text { T factor } \\
(\mathrm{T} 2-\mathrm{T} 4 / \mathrm{T} 1)\end{array}$ & 5.593 & 1.183 & 26.452 & 0.030 \\
\hline $\begin{array}{l}N \text { factor } \\
(\mathrm{N}+/ \mathrm{N}-)\end{array}$ & 2.535 & 0.643 & 9.991 & 0.184 \\
\hline $\begin{array}{l}\text { Ly factor } \\
(\text { Ly }+/ \text { Ly-) }\end{array}$ & 0.364 & 0.098 & 1.361 & 0.133 \\
\hline $\begin{array}{l}V \text { factor } \\
(V+N-)\end{array}$ & 3.351 & 1.030 & 10.903 & 0.045 \\
\hline $\begin{array}{l}\text { Histological type } \\
\text { (tub1, tub2/por, sig, others) }\end{array}$ & 0.481 & 0.184 & 1.258 & 0.136 \\
\hline $\begin{array}{l}\text { Tumor size } \\
(>34 \mathrm{~mm} /<34 \mathrm{~mm})\end{array}$ & 2.499 & 0.627 & 9.960 & 0.194 \\
\hline $\begin{array}{l}\text { The number of positive lymph nodes } \\
(>1 / \leqq 1)\end{array}$ & 0.481 & 0.133 & 1.739 & 0.265 \\
\hline
\end{tabular}

$\mathrm{Cl}$, confidence interval; $H R$, hazard ratio

\section{Discussion}

The survival rate of patients with gastric cancer has improved due to early detection and treatment $[10,11]$. As a result, more patients may develop RGC [5]. Previous studies have indicated that the pattern of reconstruction is associated with the incidence and location of the RGC $[6-8,12,13]$. However, there have been few reports on the long-term prognosis and associated clinicopathological factors of remnant gastrectomy, and its management remains controversial. Therefore, in this study, we examined the clinicopathological factors associated with the long-term outcomes of RGC.

Our findings showed that the pathological $\mathrm{T}$ stage and venous invasion were significant independent risk factors for survival among patients with RGC; however, the pathological $\mathrm{N}$ stage was not significantly associated with long-term survival. Several studies have suggested that endoscopic surveillance is crucial, because 
early detection of RGC leads to a better prognosis $[5,6$, $8,14]$. Thus, given the prognostic advantage of detecting RGC at an early $\mathrm{T}$ stage, follow-up endoscopy after distal gastrectomy is recommended for all patients. However, there is no consensus on the extent of lymphadenectomy during surgery for RGC. Since a lymph node dissection was performed in a previous surgery, the $\mathrm{N}$ factor in our current study might not be associated with the prognosis for RGC. However, in the current study, we found that venous invasion was an independent risk factor, along with the $\mathrm{T}$ stage. Nishibeppu et al. showed that venous invasion was a risk factor for recurrence after gastrectomy followed by adjuvant chemotherapy for stage III gastric cancer [15]. Another study showed that venous and nerve invasion were prognostic factors of postoperative survival in patients with resectable cancer of the rectum [16]. Based on these results, including our analysis, we believed that venous invasion could be an important risk factor for prognosis. Thus, we recommend that RGC with venous invasion should be specifically targeted to improve the prognosis of patients and suggest the possibility of it serving as an indication for more intensive treatment, such as adjuvant chemotherapy. Some studies have reported that early diagnosis and curative resection are important to improve prognosis $[17,18]$; however, there have been no studies on the association of venous invasion with worse prognosis. Therefore, evaluating venous invasion may help determine therapeutic strategies, including adjuvant chemotherapy, for RGC.

In this study, we did not test for Helicobacter pylori (HP) infection in the RGC patients. A previous study suggested that prophylactic HP eradication after endoscopic resection of early gastric cancer might be effective for preventing the development of metachronous gastric carcinoma [19]. However, the importance of HP eradication after gastrectomy remains unclear because some researchers reported that a positive HP test may be an independent risk factor for cancer recurrence [20], while other researchers indicated that HP eradication in patients with GC who underwent distal gastrectomy did not contribute to long-term postoperative survival [21]. Thus, we considered that performing follow-up endoscopy was more crucial than eradicating HP, due to the high number of elderly patients with RGC.

This study had some limitations. First, this study was a single institutional retrospective study with a relatively small sample size and limited clinical analysis of HP infection, due to our inability to obtain detailed data. Recently, some studies have been conducted regarding HP infection after gastrectomy. In the future, we should determine the relationship between RGC and $\mathrm{HP}$ infection, using accumulated prospective data.

Second, the number of patients in each category was unequal: the number of patients with initial malignant tumors was higher than that of patients with initial benign tumors. However, this difference may be attributable to the recent trend of prolonged survival in patients with cancer.

\section{Conclusions}

Although some patients had lymph node metastasis, the important prognostic factors for long-term survival of patients with RGC were the T stage and venous invasion. Therefore, they may be keys to managing and identifying therapeutic strategies for RGC to achieve better prognosis.

\section{Abbreviations}

BMI: Body mass index; CT: Computed tomography; EGD: Esophagogastroduodenoscopy; HP: Helicobacter pylori; RGC: Remnant gastric cancer.

\section{Supplementary Information}

The online version contains supplementary material available at https://doi. org/10.1186/s12957-021-02400-5.

Additional file 1: Supplemental Fig. 1. Long-term survival outcomes based on diet, history of alcohol drinking, and history of smoking.

Additional file 2: Supplemental Fig. 2. Long-term survival outcomes based on pathological T stages: (A) pathological T1 and pT2, (B) pT1 and pT3, (C) pT1and pT4, (D) pT2 and pT3, (E) pT2 and pT4, and (F) pT3 and pT4.

\section{Acknowledgements}

We would like to thank Editage (www.editage.com) for English language editing.

\section{Authors' contributions}

$\mathrm{KM}, \mathrm{RT}, \mathrm{YI}, \mathrm{KH}$, and $\mathrm{HT}$ cared for the patients and performed surgery. KM and KT designed and drafted the manuscript. SL and KU reviewed and revised the manuscript. All authors read and approved the final manuscript.

\section{Funding}

This research did not receive any specific grants from funding agencies in the public, commercial, or not-for-profit sectors.

\section{Availability of data and materials}

The datasets used during the current study are available from the corresponding author on reasonable request.

\section{Declarations}

\section{Ethics approval and consent to participate}

Written informed consent was obtained from all participants, and the study was approved by the Institutional Review Board of the Osaka Medical College (acceptance number: 2020-005) in accordance with the tenets of the Declaration of Helsinki.

Consent for publication

Not applicable. 


\section{Competing interests}

The authors declare that they have no competing interests.

\section{Author details}

${ }^{1}$ Department of General and Gastroenterological Surgery, Osaka Medical and Pharmaceutical University, 2-7 Daigaku-machi, Takatsuki, Osaka 569-8686, Japan. ${ }^{2}$ Translational Research Program, Osaka Medical and Pharmaceutical University, 2-7 Daigaku-machi, Takatsuki, Osaka 569-8686, Japan.

Received: 10 June 2021 Accepted: 15 September 2021

Published online: 27 September 2021

\section{References}

1. Ahn HS, Kim JW, Yoo MW, Park DJ, Lee HJ, Lee KU, et al. Clinicopathological features and surgical outcomes of patients with remnant gastric cancer after a distal gastrectomy. Ann Surg Oncol. 2008;15:1632-9.

2. Inomata M, Shiraishi N, Adachi Y, Yasuda K, Aramaki M, Kitano S. Gastric remnant cancer compared with primary proximal gastric cancer. Hepatogastroenterology. 2003;50:587-91.

3. Kaneko K, Kondo H, Saito D, Shirao K, Yamaguchi H, Yokota T, et al. Early gastric stump cancer following distal gastrectomy. Gut. 1998;43:342-4.

4. Kodera Y, Yamamura Y, Torii A, Uesaka K, Hirai T, Yasui K, et al. Incidence, diagnosis and significance of multiple gastric cancer. Br J Surg. 1995:82:1540-3.

5. Hanyu T, Wakai A, Ishikawa T, Ichikawa H, Kameyama H, Wakai T. Carcinoma in the remnant stomach during long-term follow-up after dista gastrectomy for gastric cancer: analysis of cumulative incidence and associated risk factors. World J Surg. 2018;42:782-7.

6. Komatsu S, Ichikawa D, Okamoto K, Ikoma D, Tsujiura M, Nishimura Y, et al. Progression of remnant gastric cancer is associated with duration of follow-up following distal gastrectomy. World J Gastroenterol. 2012;18:2832-6.

7. Zhang DW, Dong B, Li Z, Dai DQ. Clinicopathologic features of remnant gastric cancer over time following distal gastrectomy. World J Gastroenterol. 2015:21:5972-8

8. Li F, Zhang R, Liang H, Zhao J, Liu H, Quan J, et al. A retrospective clinicopathologic study of remnant gastric cancer after distal gastrectomy. Am J Clin Oncol. 2013:36:244-9.

9. Shimada H, Fukagawa T, Haga Y, Oba K. Does remnant gastric cancer really differ from primary gastric cancer? A systematic review of the literature by the Task Force of Japanese Gastric Cancer Association. Gastric Cancer. 2016;19:339-49.

10. Mao X, Xu X, Zhu H, Ji C, Lu X, Wang B. A comparison between pyloruspreserving and distal gastrectomy in surgical safety and functional benefit with gastric cancer: a systematic review and meta-analysis. World J Surg Oncol. 2020;18(1):160.
11. Xu GF, Zhang WJ, Sun Q, Xu X, Zou X, Guan W. Combined epithelialmesenchymal transition with cancer stem cell-like marker as predictors of recurrence after radical resection for gastric cancer. World J Surg Oncol. 2014;12:368.

12. Park YE, Kim SW. Clinicopathologic features of remnant gastric cancer after curative distal gastrectomy according to previous reconstruction method: a retrospective cohort study. World J Surg Oncol. 2019;17:203.

13. Tanigawa N, Nomura E, Lee SW, Kaminishi M, Sugiyama M, Aikou T, et al. Current state of gastric stump carcinoma in Japan: based on the results of a nationwide survey. World J Surg. 2010;34:1540-7.

14. Takeno S, Hashimoto T, Maki K, Shibata R, Shiwaku H, Yamana I, et al. Gastric cancer arising from the remnant stomach after distal gastrectomy: a review. World J Gastroenterol. 2014;20:13734-40.

15. Nishibeppu K, Komatsu S, Ichikawa D, Imamura T, Kosuga T, Okamoto $\mathrm{K}$, et al. Venous invasion as a risk factor for recurrence after gastrectomy followed by chemotherapy for stage III gastric cancer. BMC Cancer. 2018;18:108.

16. Knudsen JB, Nilsson T, Sprechler M, Johansen A, Christensen N. Venous and nerve invasion as prognostic factors in postoperative survival of patients with resectable cancer of the rectum. Dis Colon Rectum. 1983;26:613-7

17. Akaike H, Kawaguchi Y, Maruyama S, Shoda K, Saito R, Furuya S, et al. Mortality calculator as a possible prognostic predictor of overall survival after gastrectomy in elderly patients with gastric cancer. World J Surg Oncol. 2020;18(1):283

18. Wang Y, Huang CM, Wang JB, Zheng CH, Li P, Xie JW, et al. Survival and surgical outcomes of cardiac cancer of the remnant stomach in comparison with primary cardiac cancer. World J Surg Oncol. 2014;12:21.

19. Fukase K, Kato M, Kikuchi S, Inoue K, Uemura N, Okamoto S, et al. Effect of eradication of Helicobacter pylori on incidence of metachronous gastric carcinoma after endoscopic resection of early gastric cancer: an open-label, randomised controlled trial. Lancet (London, England). 2008;372(9636):392-7.

20. Choi Y, Kim N, Yun CY, Choi YJ, Yoon H, Shin CM, et al. Effect of Helicobacter pylori eradication after subtotal gastrectomy on the survival rate of patients with gastric cancer: follow-up for up to 15 years. Gastric Cancer. 2020;23(6):1051-63.

21. Kim YI, Cho SJ, Lee JY, Kim CG, Kook MC, Ryu KW, et al. Effect of Helicobacter pylori eradication on long-term survival after distal gastrectomy for gastric cancer. Cancer Res Treat. 2016;48(3):1020-9.

\section{Publisher's Note}

Springer Nature remains neutral with regard to jurisdictional claims in published maps and institutional affiliations.

Ready to submit your research? Choose BMC and benefit from

- fast, convenient online submission

- thorough peer review by experienced researchers in your field

- rapid publication on acceptance

- support for research data, including large and complex data types

- gold Open Access which fosters wider collaboration and increased citations

- maximum visibility for your research: over 100M website views per year

At $\mathrm{BMC}$, research is always in progress.

Learn more biomedcentral.com/submissions 